\title{
Modulation of Kv1.5 Currents by Src Tyrosine Phosphorylation: Potential Role in the Differentiation of Astrocytes
}

\author{
Stacey Nee MacFarlane and Harald Sontheimer \\ Department of Neurobiology, University of Alabama, Birmingham, Birmingham, Alabama 35294-0021
}

\begin{abstract}
Using biophysical techniques, we previously have implicated outwardly rectifying potassium currents in the proliferation of cultured spinal cord astrocytes and have demonstrated that delayed rectifier potassium currents $\left(I_{\mathrm{Kd}}\right)$, in particular, are upregulated on entry into the cell cycle and downregulated with cell cycle exit and differentiation. In the present study, using specific antibodies and antisense oligodeoxynucleotides, we show that this proliferation-dependent potassium current is mediated by the Shaker potassium channel Kv1.5. Downregulation of Kv1.5 protein by antisense oligodeoxynucleotides reduces astrocyte proliferation by $\sim 50 \%$, although no observed changes occur in Kv1.5 protein expression during spontaneous differentiation in culture. Tyrosine phosphorylation of Kv1.5, however, is downregulated markedly in differentiated cells but unaltered on cell cycle arrest. Using immunoprecipitation, we show that Kv1.5 is
\end{abstract}

associated with Src family protein tyrosine kinases and that this association does not change with cell differentiation. Inhibition of kinase activity with the Src-specific inhibitor PP2 decreases Kv1.5 phosphorylation, reduces $I_{\mathrm{Kd}}$, and inhibits astrocyte proliferation, specifically in the $\mathrm{G}_{0} / \mathrm{G}_{1}$ phase of cell cycle. Conversely, $I_{K d}$ are potentiated when active Src is present in the pipette. Transfection of quiescent astrocytes with constitutively active Src (Src Y529F) causes marked upregulation of astrocyte proliferation. These data suggest that Kv1.5 is phosphorylated constitutively by Src kinases during growth and that downregulation of Src activity may underlie both astrocyte differentiation and the accompanying changes in delayed rectifier potassium channel activity.

Key words: Src; proliferation; transfection; PP2; potassium channels; delayed rectifier
It is well established that astrocytes express an abundance of potassium currents, including voltage-gated outwardly rectifying $\left(I_{\mathrm{Kv}}\right)$, inwardly rectifying $\left(I_{\mathrm{Kir}}\right)$, and calcium-activated potassium currents (for review, see Sontheimer, 1994; Oh, 1997). Of these, the activity of delayed rectifier potassium channels $\left(\mathrm{K}_{\mathrm{d}}\right)$, has been implicated specifically in astrocyte development (Kressin et al., 1995; Akopian et al., 1997; Bordey and Sontheimer, 1997). Notably, both astrocyte proliferation and cell cycle progression are greatly reduced by the inhibition of these currents (Pappas et al., 1994; MacFarlane and Sontheimer, 1997, 2000). These previous studies have relied exclusively on biophysical and pharmacological methods. Because there are few subunit-specific channel blockers for voltage-gated potassium channels, little is known concerning the molecular identity of the channels that affect astrocyte proliferation. Consequently, even less is known about the mechanisms that regulate the activity of specific channels during astrocyte growth and differentiation. Of the potassium channel subtypes that biophysically demonstrate a delayed rectifier behavior, only two have been identified in mammalian astrocytes, both belonging to the Shaker (Kv1) subfamily of channels and both having been demonstrated only in vitro. Kv1.6 has been identified by RT-PCR in mouse cortical astrocytes (Smart et al., 1997). Antisense oligodeoxynucleotide techniques show that Kv1.5 mediates the predominant component of the delayed rectifier current in spinal cord astrocytes (Roy et al., 1996). No functional roles have been attributed to either channel type. However, there is recent evidence that Kv1.5 plays a role in the proliferation and differentiation of myelinating glial cells (Sobko et al., 1998a,b) and microglia (Kotecha and Schlichter, 1999).

Received Feb. 18, 2000; revised April 27, 2000; accepted April 29, 2000

This work was supported by National Institutes of Health Grants RO1-NS31234 and P50-HD-32901.

Correspondence should be addressed to Dr. Harald Sontheimer, University of Alabama, Birmingham, Department of Neurobiology, 1719 Sixth Avenue South, Building CIRC, Room 545, Birmingham, AL 35294-0021.E-mail: hws@nrc.uab.edu.

Dr. MacFarlane's present address: University of Pennsylvania, Department of Neuroscience, 215 Stemmler Hall, Philadelphia, PA 19104. E-mail: smacfarl@ mail.med.upenn.edu.

Copyright (C) 2000 Society for Neuroscience $\quad 0270-6474 / 00 / 205245-09 \$ 15.00 / 0$
Shaker type potassium channels can be modulated by tyrosine kinase phosphorylation (for review, see Jonas and Kaczmarek, 1996; Levitan, 1999). Because tyrosine kinase signaling plays an important role in growth and oncogenesis, it is possible that, during astrocyte growth and development, ion channels are substrates for tyrosine kinase activity. The Src family of tyrosine kinases, in particular, has been shown to affect astrocyte proliferation and oncogenesis (Trotter et al., 1989; Wiestler et al., 1989; Pomerance et al., 1994, 1995; Daub et al., 1997; Weissenberger et al., 1997).

In the present study we used antisense oligodeoxynucleotides against the Shaker subunit Kv1.5 to demonstrate that downregulation of Kv1.5 protein inhibits astrocyte proliferation, functionally implicating Kv1.5 in astrocyte proliferation. Moreover, we demonstrate that the upregulation of Kv1.5 channel activity in proliferating cells is attributable to channel phosphorylation by Src family tyrosine kinases without changes in the expression of Kv1.5 protein in the membrane.

\section{MATERIALS AND METHODS}

Cell culture. Primary cultures of spinal cord and cortical astrocytes were obtained by using methods previously described in detail (MacFarlane and Sontheimer, 1997). Briefly, postnatal day 1-3 (P1-P3) Sprague Dawley rat pups were anesthetized, and their spinal cords were dissected into cold saline solution. Then tissue was incubated for $20 \mathrm{~min}$ in an enzyme solution containing EDTA, cysteine, and $30 \mathrm{U} / \mathrm{ml}$ papain. Tissue was rinsed with EMEM supplemented with $20 \mathrm{~mm}$ glucose, $10 \%$ fetal calf serum, $1.5 \mathrm{mg} / \mathrm{ml}$ trypsin inhibitor, and $1.5 \mathrm{mg} / \mathrm{ml}$ BSA. Next the cells were plated at a density of $1.0 \times 10^{6} / \mathrm{ml}$ and grown in EMEM plus $20 \mathrm{mM}$ glucose, $10 \%$ fetal calf serum, and penicillin/streptomycin. Before reaching confluency, the purity of astrocytes was $80 \%$, with the remainder of the culture consisting of spinal cord neurons. Cultures that were more confluent were $>95 \%$ pure astrocytes.

Antisense and nonsense phosphorothioate oligodeoxynucleotide knockdown. Fully modified phosphorothioate primers were used because they confer tremendous resistance to degradation by exo- and endonucleases that are present in serum-containing media and within cells (Zon, 1995). Fluorescein-modified antisense oligodeoxynucleotide primers were designed from -9 to +11 of the $5^{\prime}$ end of Kv1.5 translation start site, with the following sequence: $\left(5^{\prime}\right)$ GAG ATC TCC ATG GTC CGG GG. These nucleotides are Kv1.5-specific and are not conserved in any other ion channel. A nonsense primer sequence was constructed from 20 randomized bases, (5') GCC CCG TAT GAC CGC GCC GG, and served as an experimental control. All primers were made, desalted, and HPLCpurified by Life Technologies Custom Primers (Rockville, MD). Astro- 


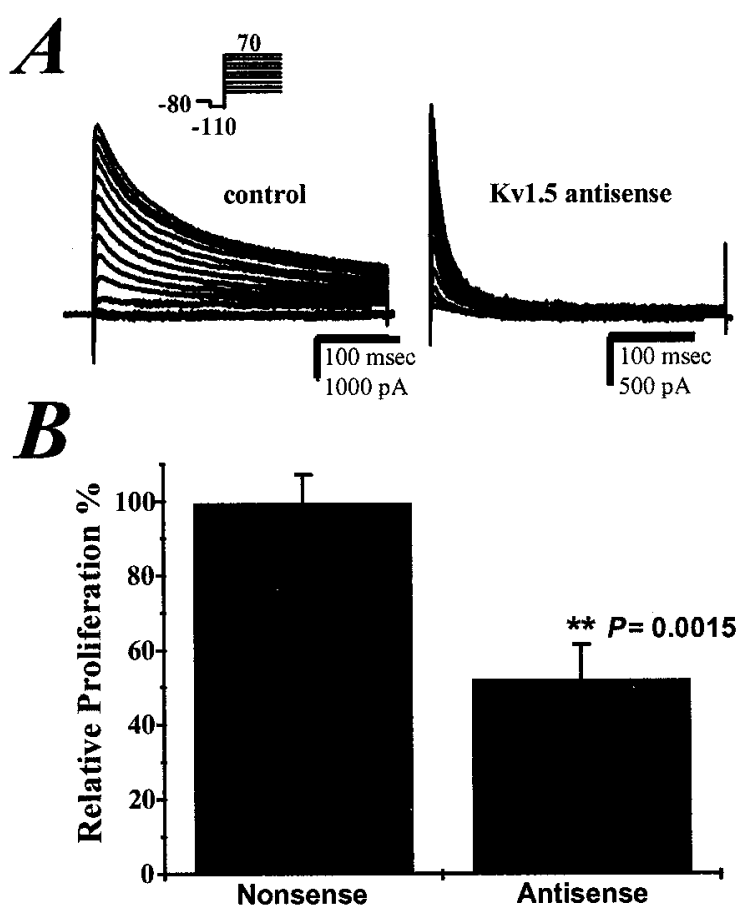

Figure 1. Kv1.5 antisense oligodeoxynucleotides inhibit astrocyte potassium currents and proliferation. $A$, Whole-cell current traces from a representative nonsense-treated control and antisense-treated cell as elicited by the voltage protocol (inset above). Antisense treatment decreased wholecell $I_{\mathrm{Kd}}$ conductance by $82 \pm 8 \%$ relative to control conductance ( $p=$ $0.0083)$. $B$, Antisense treatment significantly decreased astrocyte proliferation as assessed by counts per million of $\left[{ }^{3} \mathrm{H}\right]$ thymidine $/ \mu \mathrm{g}$ protein, expressed as a value relative to cells treated with a nonsense oligodeoxynucleotide $(p=0.0015)$.

cytes were plated at a density of 50,000 per well on a 24-well plate (Falcon, Oxnard, CA) and allowed to grow for $4 \mathrm{~d}$ in vitro (DIV). Then the astrocytes were transfected with $250 \mathrm{ng}$ of either primer and $0.75 \mu \mathrm{l}$ of FuGene 6 Transfection Reagent (Boehringer Mannheim, Indianapolis, IN) per well. DNA and FuGene were preincubated in serum-free media according to the manufacturer's protocol, and the cells were transfected with either antisense or nonsense DNA for $24 \mathrm{hr}$.

Immunocytochemistry. Cells were fixed in $4 \%$ paraformaldehyde for 15 min, rinsed six times in PBS at room temperature, and permeabilized in PBS, $0.1 \%$ Triton $\mathrm{X}-100$, and $1 \%$ goat serum for $10 \mathrm{~min}$ at room temperature. They were incubated with anti-Kv1.5 (Alomone Labs, Jerusalem, Israel) at 1:200 dilution for $2 \mathrm{hr}$ at room temperature. Primary antibody was aspirated, and the cells were rinsed three times in PBS and then reblocked in PBS plus $1 \%$ goat serum for $15 \mathrm{~min}$ at room temperature. Rhodamine-conjugated goat anti-rabbit secondary antibody (Vector Labs, Burlingame, CA) was diluted 1:1000 in PBS plus blocking serum and incubated for $2 \mathrm{hr}$ at room temperature in the dark. Coverslips were rinsed three times in PBS and mounted onto clean slides with Fluoromount $G$ (Southern Biotechnology, Birmingham, AL).

Western blot analysis. Cells were lysed on ice for $15 \mathrm{~min}$ in a protease and phosphatase inhibitor containing lysis buffer consisting of (in mM) 25 Tris base, $\mathrm{pH} 7.5,150 \mathrm{NaCl}, 100 \mathrm{NaF}, 5$ EDTA with $1 \mathrm{Na}_{3} \mathrm{VO}_{4}$, and 1 PMSF plus $2 \mu \mathrm{g} / \mathrm{ml}$ aprotinin, $1 \mu \mathrm{g} / \mathrm{ml}$ leupeptin, $1 \mu \mathrm{g} / \mathrm{ml}$ pepstatin, and $1 \%$ Triton X-100. Cell lysates were clarified by centrifugation for $5 \mathrm{~min}$ at $2000 \times g$ at $4^{\circ} \mathrm{C}$. Protein content was quantified by using the Bio-Rad protein assay (Richmond, CA), and lysates were diluted to equal protein concentrations. Lysates were boiled with Laemmli-SDS sample buffer containing $600 \mathrm{mM} \beta$-mercaptoethanol for $5 \mathrm{~min}$. Proteins were separated on a 7.5 or $8 \%$ acrylamide gel by SDS-PAGE at $120 \mathrm{~V}$ constant. Gels were transferred onto nitrocellulose paper at $200 \mathrm{~mA}$ constant for $90 \mathrm{~min}$ at room temperature and then blocked overnight in blocking buffer (BB) containing 5\% nonfat milk, $2 \%$ bovine serum albumin, and $2 \%$ normal goat serum in TBS plus $0.1 \%$ Tween 20 (TBST). Blots were incubated with primary antibody diluted according to the manufacturer's protocol in BB for $2 \mathrm{hr}$ at room temperature. They were rinsed once for $15 \mathrm{~min}$ in TBST and reblocked for $30 \mathrm{~min}$ in $\mathrm{BB}$ at room temperature. Then they were incubated with HRP-conjugated secondary antibody, where applicable, for $2 \mathrm{hr}$ at room temperature, rinsed six times for 10 min each in TBST, and developed with enhanced chemiluminescence (ECL; Amersham, Arlington Heights, IL) on Hyperfilm (Amersham). Kv1.5 polyclonal antibodies were obtained from Alomone Labs. Anti-Src family polyclonal antibody was obtained from Upstate Biotechnology (Lake Placid, NY). Anti $\alpha$-actin primary and anti-rabbit HRP-conjugated secondary antibodies were ob-
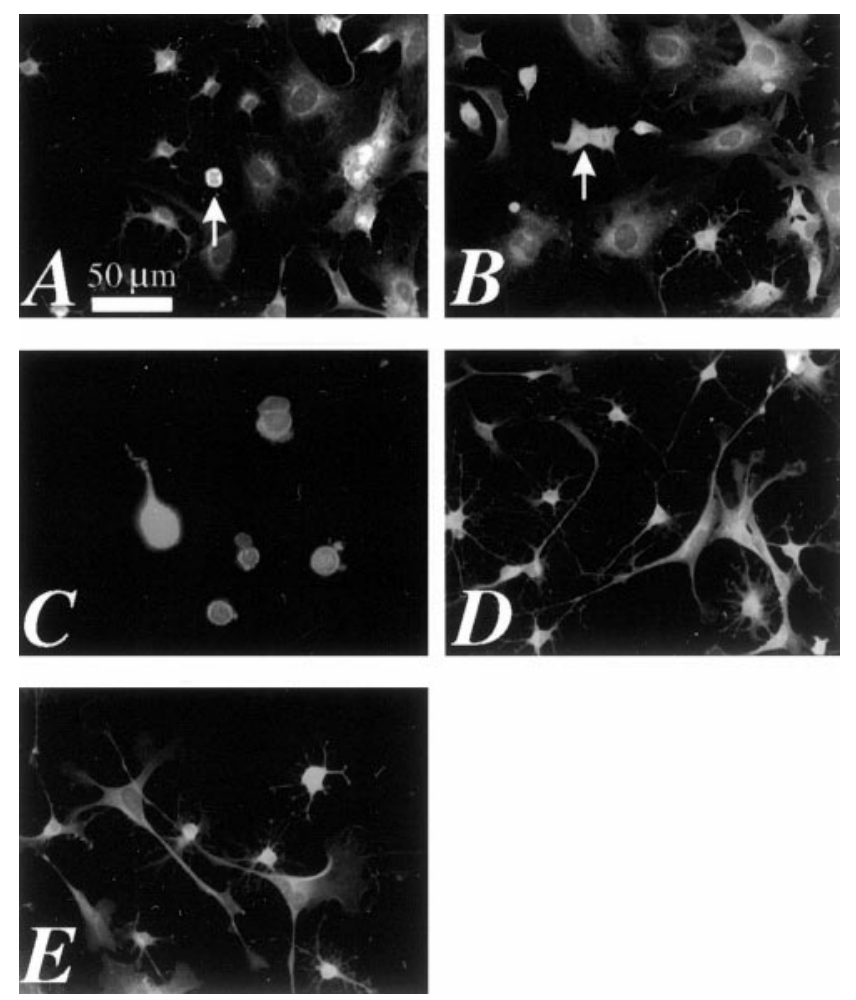

Figure 2. Immunoreactivity for Kv1.5 did not change with proliferative status. $A, B$, Proliferating astrocytes as well as actively dividing cells (arrows) demonstrate diff use Kv1.5 staining. $C$, Staining is seen in acutely dissociated spinal cord cells, implying that Kv1.5 expression is not an artifact of culture. The expression of Kv1.5 is unaltered in cells arrested in $\mathrm{G}_{0} / \mathrm{G}_{1}$ of the cell cycle by all-trans-retinoic acid $(D)$ or the potassium channel blocker TEA $(E)$.

tained from Sigma (St. Louis, MO). Anti-phosphotyrosine HRPconjugated antibody was obtained from Upstate Biotechnology.

Immunoprecipitation. Cells were lysed and clarified, and proteins were quantified according to Western protocol. Lysates were precleared overnight at $4^{\circ} \mathrm{C}$ with end-over-end rotation with protein A-conjugated beads (Pierce, Rockford, IL), $60 \mu \mathrm{l}$ of bead slurry per $1 \mathrm{ml}$ of lysate. Protein A beads were prereacted with primary antibody $(1: 1 \mathrm{v} / \mathrm{v})$ for $2 \mathrm{hr}$ at room temperature, gently spun down, and rinsed three times in PBS. Antibodyconjugated beads were reacted with the precleared cell lysate overnight at $4^{\circ} \mathrm{C}$ with end-over-end rotation. Beads were gently spun down, rinsed three times with lysate buffer, diluted in sample buffer, and boiled for $5 \mathrm{~min}$. Immunoprecipitation samples then were run on Western blot according to the above protocol.

Biotinylation. Cell cultures were rinsed twice with PBS plus $0.1 \mathrm{~mm} \mathrm{CaCl}$ and $1 \mathrm{~mm} \mathrm{MgCl}(\mathrm{PBS} / \mathrm{Ca} / \mathrm{Mg}$ ). Cells were reacted with $2 \mathrm{ml}$ of a $1 \mathrm{mg} / \mathrm{ml}$ sulfo-NHS biotin (Pierce) in PBS/Ca/Mg solution for $20 \mathrm{~min}$ at $4^{\circ} \mathrm{C}$ with gentle shaking. Biotin was aspirated off, and biotinylation was quenched by washing cells twice in $\mathrm{PBS} / \mathrm{Ca} / \mathrm{Mg}$ plus $100 \mathrm{~mm}$ glycine and then incubated in this solution for $30-45 \mathrm{~min}$ at $4^{\circ} \mathrm{C}$ with gentle shaking. Glycine solution was aspirated and the cells were rinsed, lysed, and clarified according to the Western protocol above. In all, $300 \mu$ l of lysate was reacted 1:1 v/v with Immunopure Immobilized Avidin bead suspension (Pierce) and rotated overnight at $4^{\circ} \mathrm{C}$. Beads were gently spun down, and the supernatant equaled the Intracellular Fraction, which was diluted in sample buffer and processed for Western blot analysis as above. Beads were rinsed four times with lysis buffer, diluted in sample buffer, and processed for Western blot analysis. Bead eluates constituted the biotinylated Cell Surface Fraction.

Electrophysiology. Whole-cell patch-clamp recordings were obtained by using methods previously described (MacFarlane and Sontheimer, 1997). Patch electrodes had resistances of 4-6 $\mathrm{M} \Omega$ when filled with a solution containing (in mM) $145 \mathrm{KCl}, 1 \mathrm{MgCl}_{2}, 10$ EGTA, $0.2 \mathrm{Na}$-ATP, and 10 HEPES sodium salt $\mathrm{pH}$-adjusted to 7.25 with Tris base. $\mathrm{CaCl}_{2}(0.2 \mathrm{~mm})$ was added to pipette solution just before recording, resulting in free calcium of $2.4 \mathrm{nM}$. During recordings the cells were perfused continually with a solution containing (in $\mathrm{mM}$ ) $130 \mathrm{NaCl}, 5 \mathrm{KCl}, 1.2 \mathrm{MgSO}_{4}, 1.6$ $\mathrm{Na}_{2} \mathrm{HPO}_{4}, 0.4 \mathrm{NaH}_{2} \mathrm{PO}_{4}, 1 \mathrm{CaCl}_{2}, 10.5$ glucose, and $32.5 \mathrm{HEPES}$ acid, $\mathrm{pH}$-adjusted to 7.4 with $\mathrm{NaOH}$. The upper limit for acceptable series resistance was $12 \mathrm{M} \Omega$, and series resistance compensation was adjusted to $80 \%$ to reduce voltage errors. The entrance potential of the cell served as an estimate of the resting potential of the cell, and only cells more hyperpolarized than $-60 \mathrm{mV}$ were accepted for analysis. For Src inhibition experiments, $50 \mathrm{~nm}$ 4-amino-5-(4-cholophenyl)-7-( $t$-butyl)pyrazolo- 
[3,4-d]pyrimidine (PP2; Calbiochem, La Jolla, CA) was added to the pipette solution, and the solution was kept on ice during the experiment. As a negative control for PP2 inhibition, $50 \mathrm{~nm}$ 4-amino-7-phenylpyrazolo$[3,4-d]$ pyrimidine (PP3) was added to the pipette solution (Calbiochem). For Src activation experiments, $30 \mathrm{U}$ of recombinant p60c-Src (Upstate Biotechnology) was added to the pipette solution and kept on ice until use. As previously reported (MacFarlane and Sontheimer, 2000), two distinct outward potassium currents were observed in our spinal cord astrocyte cultures that could be isolated biophysically by standard procedures. Outward currents were elicited by a voltage protocol that stepped the membrane from a holding potential of -80 to $-110 \mathrm{mV}$ for $40 \mathrm{msec}$ and then to voltages ranging from -60 to $70 \mathrm{mV}$ for $200 \mathrm{msec}$. Then currents were elicited again by the same voltage protocol but from a prepulse potential of $-50 \mathrm{mV}$. The delayed rectifier current was defined as the steady-state current elicited from a test voltage of $70 \mathrm{mV}$ and measured at $190 \mathrm{msec}$ into the second epoch. Point-by-point subtraction of the current obtained from the prepulse of $-50 \mathrm{mV}$ from that obtained with the prepulse to $-110 \mathrm{mV}$ permitted isolation of the transient potassium current, which was measured as the peak subtracted current elicited from a test voltage of $70 \mathrm{mV}$. Conductance was calculated by dividing peak current by ionic driving force. Specific conductance was calculated by dividing whole-cell conductance by whole-cell capacitance.

Transfection. Confluent astrocyte monolayers that were at least 26 DIV were transfected with a constitutively activated Src (Src Y529F) in a pUSE vector (Upstate Biotechnology). Src vector was mixed 1:1 v/v with green fluorescent protein (GFP) vector (Qiagen, Chatsworth, CA) in serum-free media according to the FuGene liposome protocol. Each well of a 24-well plate (Falcon) was transfected with $250 \mathrm{ng}$ of total DNA for $24 \mathrm{hr}$; transfection efficiency was evaluated by fluorescence microscopy. Control cells were transfected with GFP vector alone, according to FuGene protocol.

Proliferation assays. Incorporation of $\left[{ }^{3} \mathrm{H}\right]$ thymidine was used as quantitative measure of cell proliferation. Cells were incubated with $1 \mu \mathrm{Ci} / \mathrm{ml}$ radiolabeled thymidine $\left(\left[\right.\right.$ methyl- $\left.{ }^{3} \mathrm{H}\right]$ thymidine) for $240 \mathrm{~min}\left(\right.$ at $\left.37^{\circ} \mathrm{C}\right)$. Culture dishes were rinsed three times with PBS and solubilized with $0.3 \mathrm{~N}$ $\mathrm{NaOH}$ for $30 \mathrm{~min}$ at $37^{\circ} \mathrm{C}$. Lysates were neutralized by the addition of $0.3 \mathrm{~N}$ $\mathrm{HCl}$. An aliquot from each sample was used for cell protein determination with the Bio-Rad protein assay reagent. The remaining lysate was mixed with ScintiVerse (Fisher Scientific, Houston, TX), and radioactivity was determined in a scintillation counter. For each individual sample, counts per million were normalized for protein concentration $(\mathrm{cpm} / \mu \mathrm{g})$.

Flow cytometry. Cells grown $<5$ DIV were treated for $24 \mathrm{hr}$ with the Src-specific inhibitor PP2. After treatment the cells were harvested by trypsinization $(0.025 \%)$, rinsed three times with cold PBS, fixed for $1 \mathrm{hr}$ at $4^{\circ} \mathrm{C}$ in $70 \%$ ethanol, rinsed, and incubated with propidium iodide (Boehringer Mannheim) plus $50 \mu \mathrm{g} / \mathrm{ml}$ RNase in the dark for $1 \mathrm{hr}$. Fluorescenceactivated cell sorting (FACS) was performed on a FACS caliber sorter (Becton Dickinson, San Jose, CA) by using Modfit software (Varity). The analysis calculates the percentage of cells in a stage of cell cycle, based on the concentration of propidium iodide fluorescence such that cells in $\mathrm{G}_{0} / \mathrm{G}_{1}, \mathrm{G}_{2}+\mathrm{M}$, and $\mathrm{S}$ would quantify as fluorescent peaks at $x, 2 x$, and $x<$ $y<2 x$, respectively.

Statistical analysis. All statistical analysis was performed with GraphPAD (InStat, San Diego, CA) software. Student's two-tailed, unpaired $t$ test was used to compare pairs of data sets that followed normal SD distribution; exact $p$ values are given for Student's $t$ test comparisons. ANOVA was used for multiple comparisons or for data that did not have normal SD distributions, and Bonferroni corrected $p$ values are given for ANOVA tests. All value are reported as mean $\pm \mathrm{SE}$, where $n$ is the number of cells or experiments.

\section{RESULTS}

\section{Potential role for Kv1.5 in astrocyte proliferation}

Kv1.5 antisense knockdown previously has been shown to inhibit $\sim 50 \%$ of the delayed rectifier potassium current in spinal cord astrocytes (Roy et al., 1996). We not only confirmed these findings but report enhanced current knockdown with the use of lower DNA concentrations and a nonliposomal transfection reagent. A representative whole-cell recording from an antisense-treated cell compared with currents from a proliferating cell treated with nonsense control oligodeoxynucleotides demonstrates that the inactivating delayed rectifier current is markedly reduced (Fig. 1A). On average, the delayed rectifier currents in actively proliferating astrocytes were decreased by $82 \pm 8 \%$ with Kv1.5 antisense phosphorothioate oligodeoxynucleotide treatment. In addition, antisense knockdown of Kv1.5 decreased proliferation of astrocytes by $48 \%$ as assessed by $\left[{ }^{3} \mathrm{H}\right]$ thymidine incorporation in comparison to cells treated with a nonsense 20 -mer that did not correspond to the sequence of any known ion channel $(n=10$ experiments; $p=$ 0.0015; Fig. $1 B$ ).

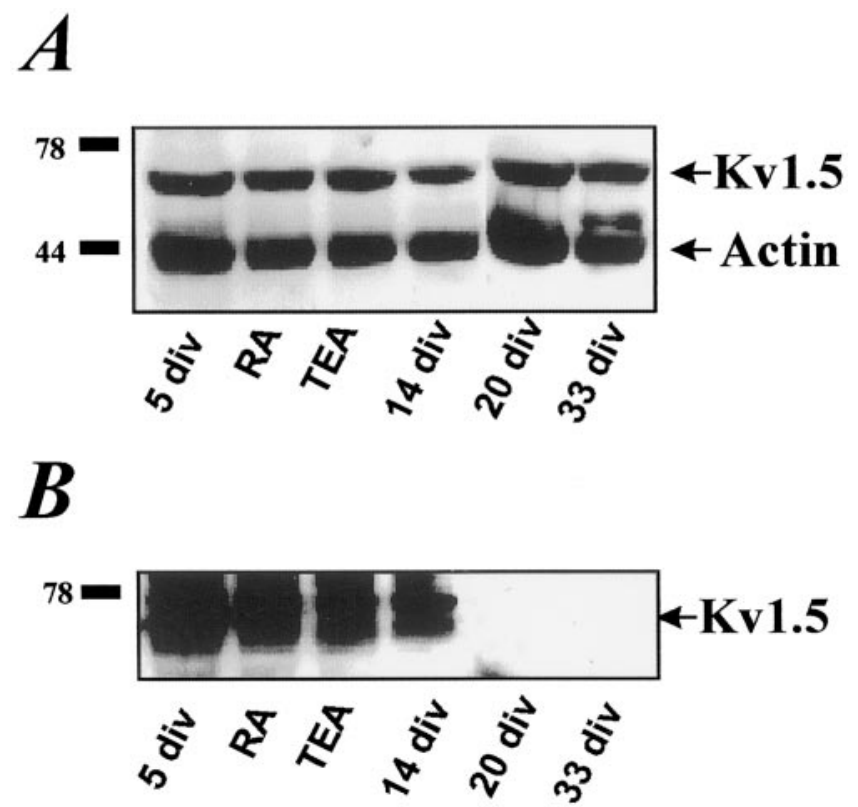

Figure 3. Kv1.5 protein expression is unaltered during astrocyte differentiation. $A$, A protein band at a molecular weight of $67 \mathrm{kDa}$ was specific for Kv1.5 immunoreactivity and was unaltered neither on cell cycle arrest with RA or TEA nor on differentiation in culture up to 33 DIV. A band at $\sim 42$ $\mathrm{kDa}$, corresponding to $\alpha$-actin, was used as a loading control. $B$, The same immunoblot reprobed with a mouse monoclonal for phosphotyrosine clone 4 G10. Kv1.5 protein is differentially tyrosine-phosphorylated at 20 and 33 DIV, a time at which cultures become quiescent.

\section{Changes in Kv1.5 protein expression do not accompany proliferation-associated changes in $\mathrm{K}^{+}$currents}

We wanted to ascertain whether the observed changes in potassium channel activity during proliferation correspond to changes in Kv1.5 protein expression. Because we could not follow individual cells through the cell cycle, we treated actively proliferating astrocytes $(<5$ DIV) with reagents that we previously had confirmed to inhibit astrocyte progression in the $G_{0} / G_{1}$ phases of the cell cycle (MacFarlane and Sontheimer, 2000). Specifically, we used the differentiating reagent all-trans-retinoic acid (RA) and the potassium channel blocker tetraethylammonium (TEA), which inhibit the astrocyte delayed rectifier current (MacFarlane and Sontheimer, 1997). Both reagents also prevent the start of the cell cycle as well as the accompanying upregulation of delayed rectifier channel activity (MacFarlane and Sontheimer, 2000). After treatment the cells were fixed, and immunocytochemical cell staining was performed by using Kv1.5 antibodies. Immunoreactivity for Kv1.5 did not change on cell cycle arrest (Fig. $2 A-E$ ), because actively proliferating (Fig. 2A,B), retinoic acid-arrested (Fig. 2D), and TEA-arrested cells (Fig. $2 E$ ) all displayed prominent Kv1.5 expression. Furthermore, Kv1.5 immunoreactivity of cultured cells was similar to that of acutely dissociated cells (Fig. $2 C$ ), suggesting that the observed Kv1.5 expression was not induced by cell culture.

At 5 DIV, astrocytes were still actively proliferating and displayed prominent delayed rectifier currents, but on reaching confluence at $\sim 8$ DIV the whole-cell conductance of the delayed rectifier was markedly reduced (Ransom and Sontheimer, 1995; Roy and Sontheimer, 1995; MacFarlane and Sontheimer, 2000). Western blot analysis was performed to see whether decreased current correlated with altered expression of Kv1.5 protein. Cell lysates were obtained from cells grown for 5 DIV, from sister cultures that were treated with either RA or TEA, and from cells that were grown to confluence at 14, 20, and 33 DIV. Then proteins were immunoblotted and probed with a specific antibody for Kv1.5 (Fig. $3 A$ ). Kv1.5 protein expression was neither altered by cell cycle arrest nor changed with progressive differentiation in culture (Fig. $3 A$ ). A specific immunoreactive band was observed at $67 \mathrm{kDa}$, 


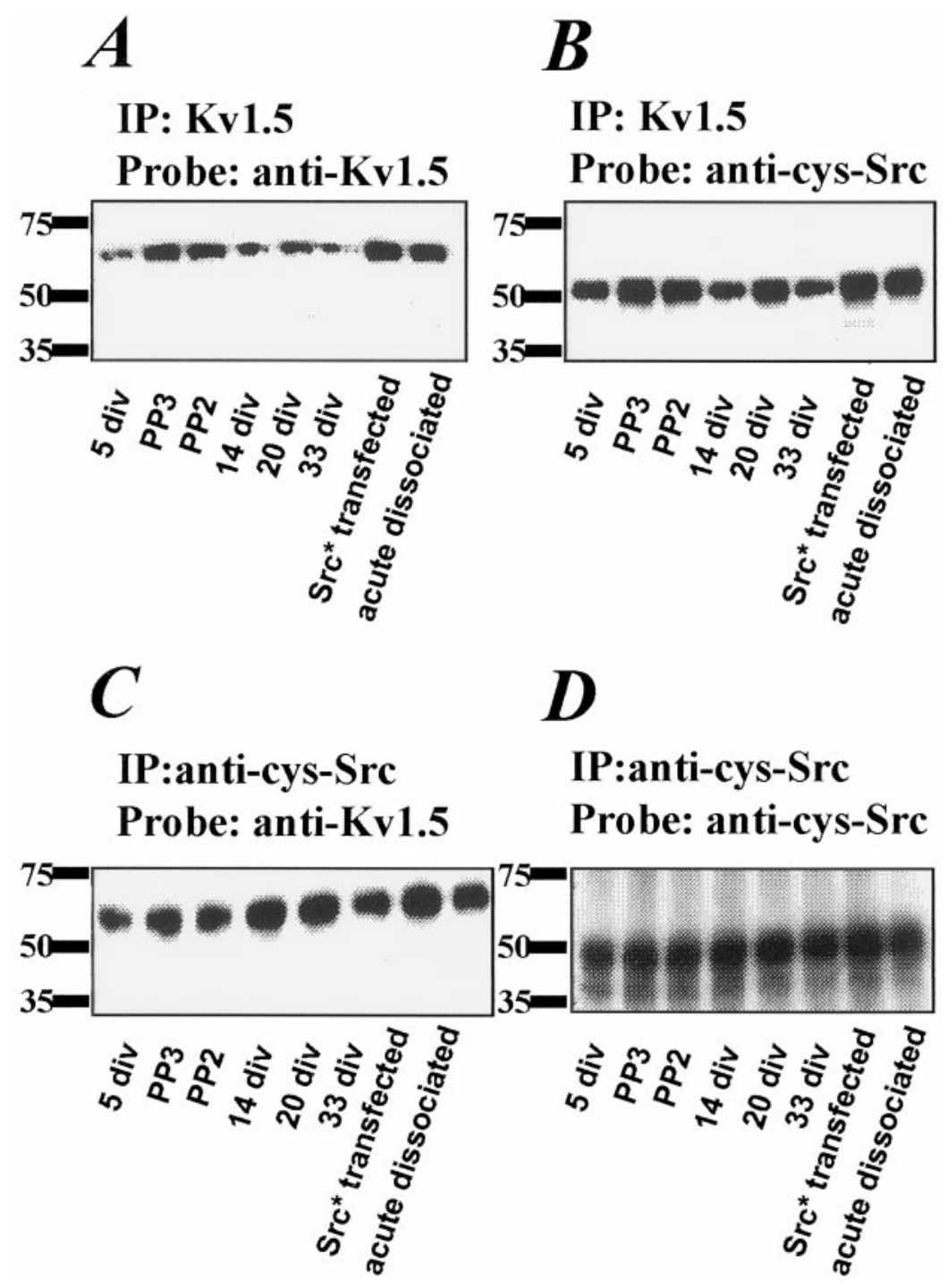

Figure 4. Coprecipitation of Kv1.5 and native Src throughout astrocyte differentiation. $A$, Immobilized Kv1.5 antibody is able to precipitate Kv1.5 channel protein in actively proliferating cells $(5 D I V)$, throughout differentiation (at 14,20 , and 33 $D I V)$, in astrocytes transfected with active Src, and in acutely dissociated spinal cord tissue. $B$, A protein of $\sim 55 \mathrm{kDa}$ coprecipitates with Kv1.5 channel. This band demonstrates specific immunoreactivity for cys-Src polyclonal antibody, which recognizes the conserved autophosphorylation site of multiple Src family kinases. Coprecipitation is unaffected by differentiation in culture. There is no difference of association between Kv1.5 and Src kinases in cells treated with the Src-specific kinase inhibitor PP2 versus an inactive control compound, PP3. $C, D$, Conversely, Kv1.5 protein can be coprecipitated with anti-cysSrc antibody.

corresponding to the molecular weight of rat Kv1.5, and this band was eliminated when antibody was preabsorbed with control antigen (data not shown). An immunoreactive band at $\sim 42 \mathrm{kDa}$ was specific for $\alpha$-actin and was used as a loading control (Fig. $3 A$ ).

\section{Kv1.5 tyrosine phosphorylation is altered during differentiation}

Because alteration of channel protein expression cannot account for the dramatic changes in current expression observed electrophysiologically (MacFarlane and Sontheimer, 1997, 2000), we set out to investigate whether Kv1.5 is functionally modulated during growth and development. The rat Kv1.5 sequence contains a number of potential sites for phosphorylation that are substrates for a wide range of kinases (PepTool, BioTools, Edmonton, Alberta, Canada). Because tyrosine kinases are well known for their role in the control of growth and development in the nervous system and have been shown to modulate human and mouse Kv1.5 currents, we specifically focused on investigating potential protein tyrosine kinase phosphorylation of Kv1.5. Using a mouse monoclonal antibody for phosphotyrosine (clone 4G10), we probed cell lysates from subconfluent proliferating astrocytes $(<5$ DIV), retinoic acid or TEA-treated sister cultures, and lysates from confluent nonproliferating astrocytes at 14, 20, and 33 DIV. There was no significant difference in tyrosine phosphorylation of Kv1.5 in actively proliferating or cell cycle-arrested cells (Fig. 3B). Cell lysates from 5 DIV, retinoic acid arrest, and TEA arrest all demonstrated phosphotyrosine immunoreactivity of a $67 \mathrm{kDa}$ protein that was iden- tified as Kv1.5 (Fig. 3B). However, at 20 and 33 DIV, Kv1.5 no longer demonstrated immunoreactivity for phosphorylated tyrosine (Fig. 3B), suggesting that tyrosine phosphorylation of Kv1.5 is reduced in astrocytes on differentiation in culture.

\section{Native Src family kinases associate with Kv1.5}

The Src family of tyrosine kinases is known to be expressed in astrocytes, where they play a role in growth control (Pomerance et al., 1994). Transgenic mice with v-Src kinase under control of the glial fibrillary acidic protein (GFAP) gene regulatory element develop malignant astrocytomas (Weissenberger et al., 1997). To investigate whether Src is associated with Kv1.5, we performed immunoprecipitation with Kv1.5 antibody-coated protein A beads and then probed the eluates by using a polyclonal antibody raised against the conserved autophosphorylation site of p60c-Src (amino acids 403-421), which recognizes multiple Src family members that range in molecular weight from 55 to $62 \mathrm{kDa}$ (Upstate Biotechnology). This antibody was chosen over a specific antibody against Src because more than one Src-like kinase has been identified in astrocytes, and this antibody allows for the detection of multiple Src family members. Using antibodies for Kv1.5, we were able to precipitate a band at $67 \mathrm{kDa}$ specific for Kv1.5 (Fig. $4 A$ ), as well as a protein weighing $\sim 55 \mathrm{kDa}$ that demonstrates specific immunoreactivity for anti-Src family antibody (Fig. 4B). Similarly, Kv1.5 can be immunoprecipitated conversely with anti-Src family antibody (Fig. $4 C, D$ ). It is important to note that the apparent expression of Src kinases does not change with astrocyte differentiation. 


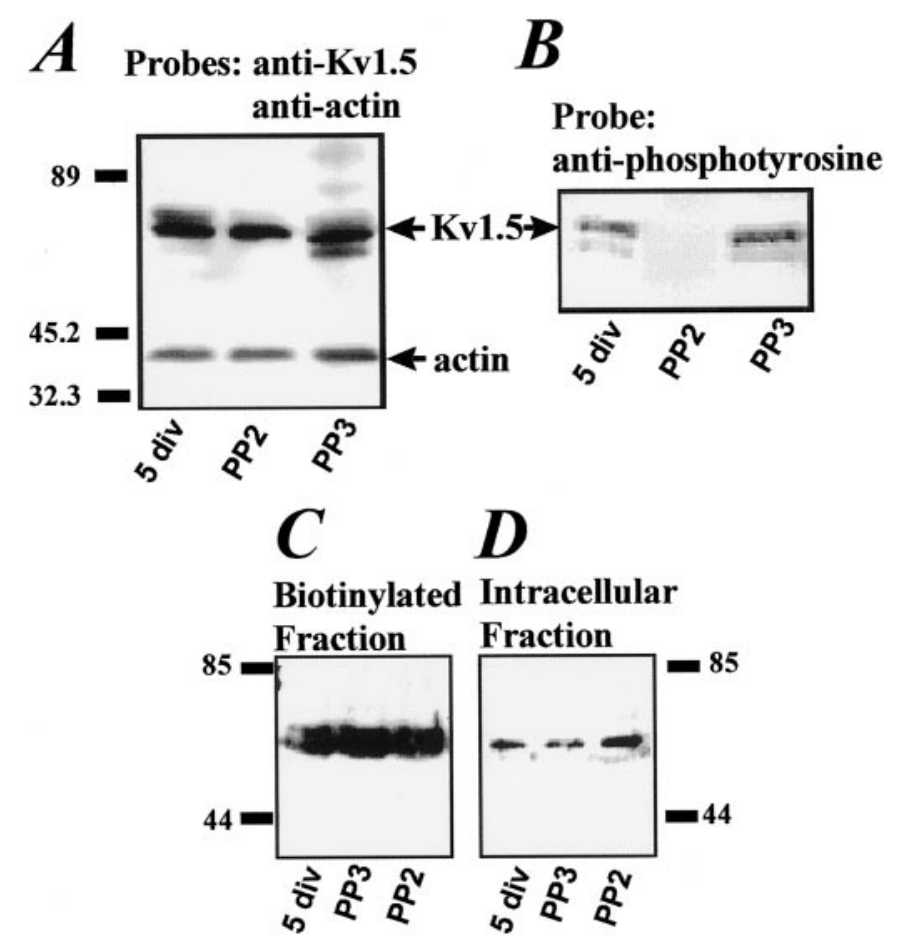

Figure 5. Src family-specific inhibitor PP2 decreases phosphorylation of Kv1.5 without affecting channel expression within the membrane. $A$, Kv1.5 protein levels in cell lysates are unaltered by incubation with the Src-specific inhibitor PP2. B, Tyrosine phosphorylation of Kv1.5 is downregulated by incubation with PP2 but is unaffected by the inactive control PP3. C, Incubation with PP2 does not affect the number of Kv1.5 channels in either the biotinylated membrane fraction or the intracellular fraction $(D)$ of cell lysates.

Taken together, these data suggest that there is an association between Kv1.5 and native Src family kinases because the two are able to coimmunoprecipitate, and this association does not change over development in culture because lysates from cells at 5, 14, 20, and 30 DIV equally coprecipitated Src family proteins with Kv1.5 channel protein. In addition, the Src family-specific inhibitor PP2 did not alter this interaction relative to a structurally similar inactive control compound, PP3, implying that the interaction between Src and Kv1.5 did not depend on Src phosphorylation. Conversely, the coprecipitation was not enhanced when astrocytes were transfected with recombinant constitutively activated Src (Src Y529F). This interaction is also not an artifact of culture because native Kv1.5 and Src were coimmunoprecipitated from lysates obtained from acutely dissected spinal cord tissue, demonstrating an association between Src and Kv1.5 in vivo.

\section{Kv1.5 tyrosine phosphorylation is downregulated by a Src-specific kinase inhibitor}

Although treatment of astrocytes with the Src family-specific inhibitor PP2 (50 nM for $24 \mathrm{hr}$ ) had no effect on protein expression levels of Kv1.5 (Fig. $5 A$ ), it inhibited Kv1.5 tyrosine phosphorylation (Fig. $5 B$ ). Because PP2 is very stable and cannot be inactivated by boiling, an inactive but structurally similar compound, PP3, was used as a negative control. PP3 (50 nM) affected neither protein levels nor tyrosine phosphorylation of Kv1.5 (Fig. 5A,B). Changes in phosphorylation have been shown to affect the accumulation of channel proteins in the plasma membrane (Ivanina et al., 1994; Levin et al., 1995). To assess whether levels of Kv1.5 in the plasma membrane or intracellular fractions were altered on treatment with the Src kinase inhibitor PP2, we undertook biotinylation studies in which surface membrane proteins were biotinylated biochemically, separated by using immobilized avidin, and then analyzed by Western blot. On treatment for $24 \mathrm{hr}$ with PP2, there were no changes in the apparent protein levels of Kv1.5 in either the biotinylated (Fig. 5C) or intracellular fractions as compared with untreated and PP3-treated controls (Fig. 5D). Note that there was an increase in the apparent molecular weight $(\sim 5 \mathrm{kDa})$ for the biotinylated proteins (Fig. $5 C$ ) as compared with the intracellular fraction of Kv1.5 (Fig. 5D). This is consistent with the addition of multiple biotin molecules and has been demonstrated for other integral proteins by using this protocol (Ye et al., 1999).

\section{Src-specific phosphorylation/dephosphorylation acutely affects delayed rectifier currents}

Because Kv1.5 is known to mediate a component of the astrocyte delayed rectifier current and can be phosphorylated by Src and dephosphorylated by PP2, we next wanted to assess what effects, if any, tyrosine phosphorylation had on astrocyte delayed rectifier currents. By using whole-cell voltage-clamp recordings of actively proliferating astrocytes $(<5$ DIV) with the Src inhibitor PP2 in the pipette solution, we observed marked changes in whole-cell potassium conductance. The delayed rectifier whole-cell conductance was reduced by $44 \pm 7 \%$ within $19 \pm 2$ min after patch rupture $(n=14$; Fig. $6 A)$. Within 2 min after patch rupture the average whole-cell steady-state conductance of the delayed rectifier was $637 \pm 66 \mathrm{pS} / \mathrm{pF}$, but as PP2 dialyzed into the cell, average wholecell conductance was reduced to $373 \pm 67 \mathrm{pS} / \mathrm{pF}(n=14 ; p=$ $0.0094)$. In contrast, the whole-cell conductance of the transient outward potassium current was unchanged, $1.56 \pm 0.25 \mathrm{nS} / \mathrm{pF}$ versus $1.67 \pm 0.30 \mathrm{nS} / \mathrm{pF}$ after pipette dialysis $(n=14 ; p=0.78)$. Current subtraction shows that the PP2-sensitive current is an outwardly rectifying potassium current (Fig. 6B), reminiscent of the sustained delayed rectifier current previously characterized in these cells (MacFarlane and Sontheimer, 1997) and similar to the current carried by Kv1.5 (Roy et al., 1996).

To demonstrate further that the effects of PP2 on delayed rectifier currents were indeed attributable to Src tyrosine kinase inhibition, we wanted to see whether the converse treatment would have an opposing effect. We used astrocyte cultures that had reached confluence, a time when delayed rectifier currents typically are downregulated; whole-cell voltage-clamp recordings were performed with activated recombinant Src in the pipette (Upstate Biotechnology). Currents were recorded within 2 min on reaching whole-cell configuration. Within 23 min after patch membrane rupture the whole-cell delayed outwardly rectifying potassium conductance nearly doubled (Fig. 7A), from an average of $209 \pm 47$ $\mathrm{pS} / \mathrm{pF}$ to $409 \pm 88 \mathrm{pS} / \mathrm{pF}(n=7 ; p=0.05)$. Note well that basal delayed rectifier whole-cell conductance was markedly reduced in quiescent cells relative to actively proliferating cells (above); this corresponded well with previous reports demonstrating an approximate threefold increase of delayed rectifier whole-cell conductance in proliferating cells as compared with nonproliferating cells (MacFarlane and Sontheimer, 1997). Interestingly, the whole-cell conductance for the transient outwardly rectifying potassium current also increased $33 \pm 13 \%(n=9)$; however, because at this developmental stage the magnitude of $\mathrm{K}_{\mathrm{A}}$ varied tremendously from cell to cell, there was no significant difference between the average conductance before $(433 \pm 180 \mathrm{pS} / \mathrm{pF})$ and after the Src-mediated increase $(493 \pm 183 \mathrm{pS} / \mathrm{pF} ; n=9 ; p=0.82)$. The isolated Srcinduced current was predominantly a noninactivating delayed rectifier current (Fig. 7B).

\section{Functional link between tyrosine phosphorylation by Src and proliferation}

To assess whether the observed changes in whole-cell potassium conductance had any functional significance for astrocyte proliferation, we treated actively proliferating cells with PP2 for $24 \mathrm{hr}$ and elicited a reduction of astrocyte proliferation by $50 \%(n=24 ; p<$ 0.001 ) whereas PP3 had no effect (Fig. 8A). Likewise, PP2 caused a significant increase in the number of astrocytes accumulated in the $\mathrm{G}_{0} / \mathrm{G}_{1}$ stage of cell cycle $(12 \%$ increase; $p=0.01)$ and a concomitant $10 \%$ decrease $(p<0.02)$ in the number of cells in S-phase as compared with control untreated cells (Fig. $8 B$ ), suggesting that the specific inhibition of Src kinases decreased astro- 


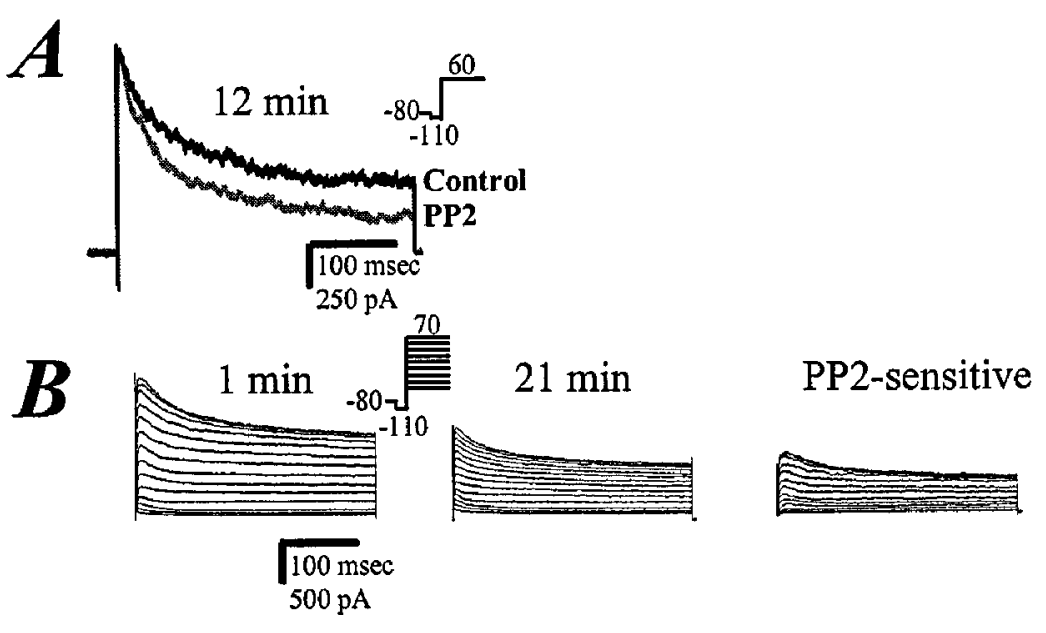

Figure 6. Src inhibitor acutely decreases Kv1.5 currents. $A$, Representative recording of currents in response to the voltage protocols shown (insets to the right). Currents were recorded after achieving whole-cell configuration (Control) and at 12 min after dialyzing with PP2 in the patch pipette $(P P 2) . B$, Isolation of the PP2-sensitive current (right) by point-by-point subtraction of the whole-cell currents at 21 min with PP2 in the pipette (middle) from the currents at patch membrane rupture (left). The PP2-sensitive current is mainly a sustained outwardly rectifying potassium current.
Figure 7. Increased Src activity increases Kv1.5 currents. $A$, Representative recording of currents in response to the voltage protocols shown (insets to the right). Currents were recorded within $1 \mathrm{~min}$ of achieving whole-cell configuration (Control) and at $35 \mathrm{~min}$ after dialyzing with active Src in the patch pipette $(S r c)$. B, Isolation of the Src-induced current by pointby-point subtraction of the whole-cell currents at $1 \mathrm{~min}$ (left) from currents at $26 \mathrm{~min}$ (middle) after patch membrane rupture indicates that the Src-induced current (right) is predominantly a sustained outwardly rectifying potassium current.
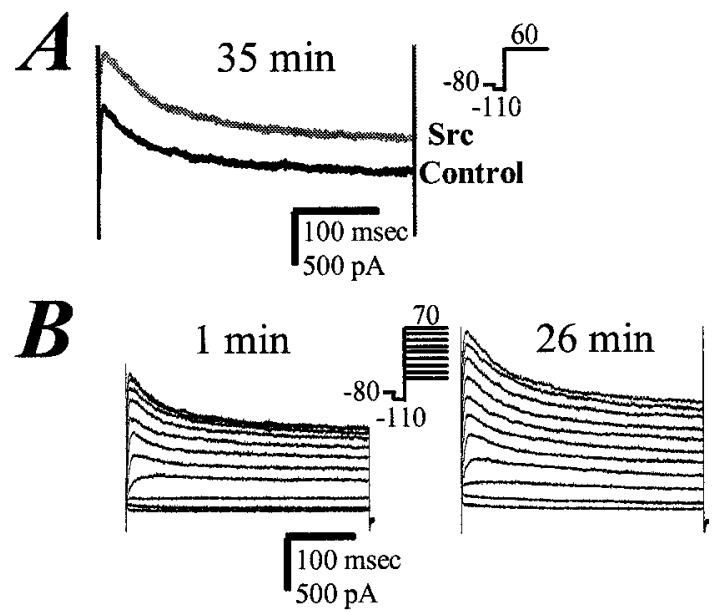

Src-induced

Kv1.5 markedly reduced cell proliferation, directly implicating Kv1.5 function in astrocyte proliferation. Interestingly, in spontaneously proliferating cells no change in Kv1.5 protein levels was observed on differentiation; however, we observed differential tyrosine phosphorylation in proliferating versus quiescent astrocytes. Further examination revealed that rat Kv1.5 is associated with Src family kinases, which constitutively phosphorylate Kv1.5 during proliferation. The inhibition of Src decreases phosphorylation of Kv1.5, acutely downregulates Kv1.5 currents, and decreases proliferation. Taken together, these data suggest that Kv1.5 and Src coexist in a modulatory complex and that this complex may be involved in the translation of tyrosine kinase growth signaling into the subsequent changes in channel activity accompanying astrocyte proliferation.

Reversible phosphorylation of Shaker potassium channels by native Src kinases has been linked to cell function in other cell types, with the vast majority of these studies focusing on the subunit Kv1.3. In all of these studies Src kinase activity suppresses Kv1.3 currents, coinciding with apoptosis in T-lymphocytes (Szabo et al., 1996, 1997; Gulbins et al., 1997) and modulation of olfactory bulb neuron excitability (Fadool, 1998). A role for Src in glial proliferation previously has been demonstrated in Schwann cells, where the Src family of protein tyrosine kinases constitutively activates Kv1.5 and broad-spectrum tyrosine kinase inhibitors downregulate Schwann cell proliferation (Sobko et al., 1998). The antiproliferative effects of these general tyrosine kinase inhibitors are mediated, in part, by a reduction in Kv1.5 tyrosine phosphorylation and reduced amplitude of the delayed rectifier current (Peretz et al., 1999). Conversely, stable expression of v-Src in murine glial precursors arrests cell development and causes the cells to retain the exclusive expression of outward potassium currents (Trotter et al., 1989), which is the current profile of a prolif-
By using antisense oligonucleotides against Kv1.5, we demonstrate that the vast majority of delayed outwardly rectifying potassium currents in immature dividing astrocytes is mediated by the rat homolog of the Shaker Kv1.5 channel. Moreover, knockdown of 
$\boldsymbol{A}$

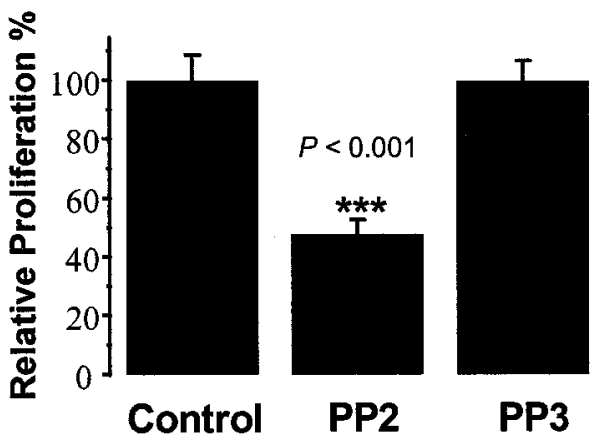

$\boldsymbol{B}$

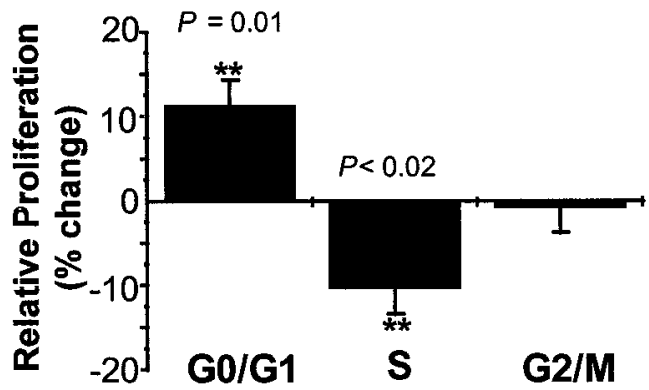

Figure 8. Src activity affects astrocyte proliferation. $A$, Proliferation as assessed by $\left[{ }^{3} \mathrm{H}\right]$ thymidine incorporation per microgram of protein and normalized to untreated control values. Cells incubated with the Srcspecific inhibitor PP2 demonstrate decreased proliferation relative to cells treated with an inactive compound (PP3), which demonstrate no difference over untreated cells (Control). B, FACS analysis of PP2-treated cells reveals that inhibition of Src activity causes a $10 \%$ increase in the number of cells in $\mathrm{G}_{0} / \mathrm{G}_{1}$ phases of the cell cycle and a concomitant $10 \%$ decrease in the number of cells in S-phase, suggesting that Src kinase activity is particularly critical for astrocyte progression beyond the $G_{1} / S$ checkpoint.

erating phenotype (Sontheimer et al., 1989). These findings are in good agreement with the data in the present study, in which we demonstrate that Src-specific inhibition accounts for the reduction of Kv1.5 whole-cell conductance and implicate Src specifically in astrocyte proliferation. Other studies using recombinant expression, however, have shown that when $\mathrm{v}$-Src is heterologously coexpressed with human Kv1.5 the channel demonstrates tyrosine phosphorylation but Kv1.5-mediated currents are reduced, with no alteration of channel protein expression (Holmes et al., 1997). We suggest that Src-mediated increases in Kv1.5 activity in native systems may indicate the involvement of a signaling complex that is absent in heterologously transfected cells. Heterologously expressed human Kv1.5 has been shown to associate directly with coexpressed Src protein tyrosine kinase via the SH3 domain (Holmes et al., 1997), but the rat sequence lacks this SH3 consensus sequence. We attempt to compensate for the discrepancy by suggesting that Src family kinase association with rat Kv1.5 potentially occurs by means other than SH3-mediated association, either directly via another motif or indirectly via some unknown Src and Kv1.5 signaling complex.

In our study, Src family kinase tyrosine phosphorylation appears to mediate the changes in Kv1.5 activity that are seen during development and differentiation in culture but does not mediate the transient changes occurring during the cell cycle. This is consistent with a role for Src in astrocytic growth factor-dependent signal pathways (Pomerance et al., 1994; Cazaubon et al., 1997; Daub et al., 1997; Kobierski et al., 1999). Roles for Src activity in cell cycle regulation have been identified in other cell types, with the evi-

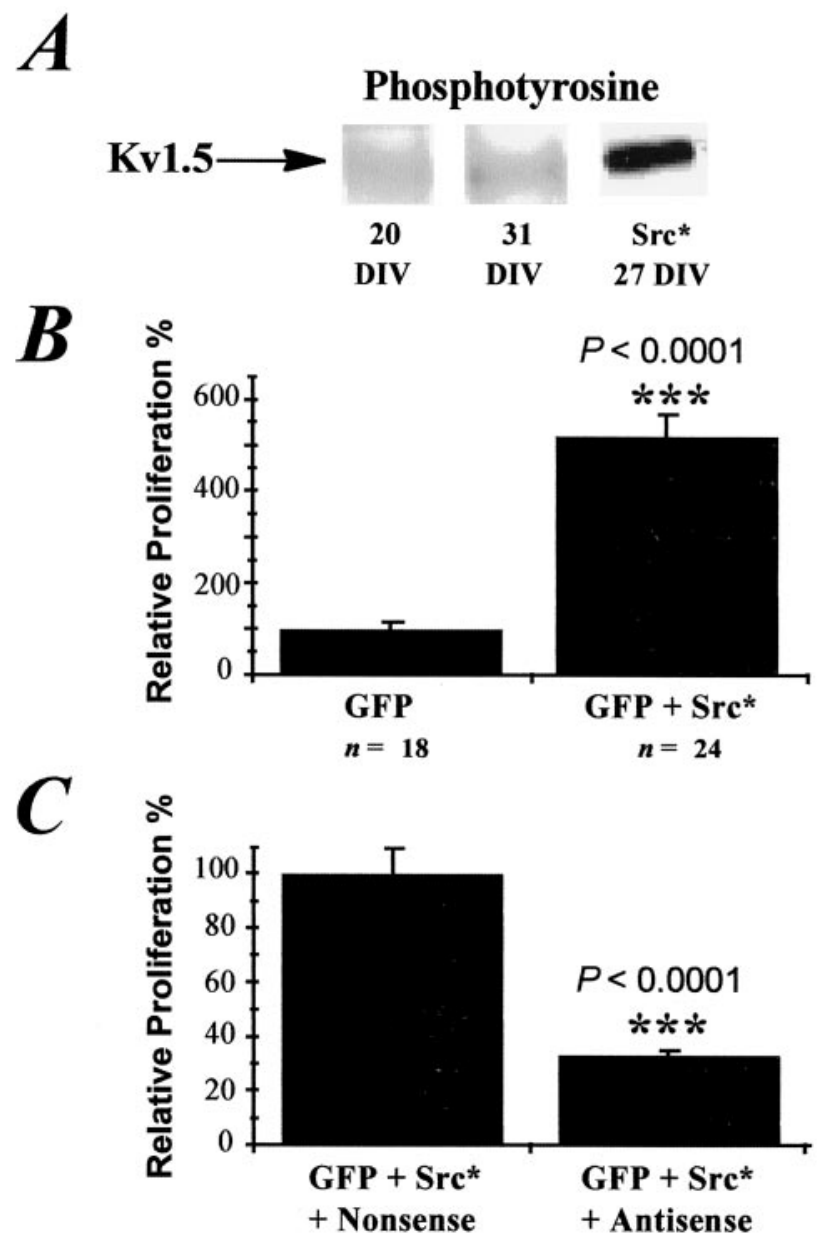

Figure 9. Increased Src activity increases astrocyte proliferation. $A$, Transfecting Src Y529F, a constitutively active Src $\left(S r c^{*}\right)$, into quiescent astrocytes $(27 \mathrm{DIV})$ restores immunoreactivity of Kv1.5 for phosphotyrosine, as analyzed by Western blot. $B$, Astrocytes cotransfected with Src* and green fluorescent protein $(G F P)$ demonstrate significantly increased proliferation over GFP-transfected cells alone. $C$, On transfection with Src*, treating astrocytes with Kv1.5 antisense oligodeoxynucleotides partially inhibits the increase in proliferation as compared with cells treated with a nonsense oligodeoxynucleotide as control.

dence suggesting that Src kinase activity is increased during $G_{1}$ phase of cell cycle and is required for the progression through early phases of mitotic division (Fumagalli et al., 1994; Moasser et al., 1999). Our data demonstrating that Kv1.5 is tyrosinephosphorylated during $\mathrm{G}_{1}$ arrest are consistent with increased Src kinase activity at this stage of the cell cycle. We suggest that the changes in Kv1.5 activity that are observed during cell cycle progression (MacFarlane and Sontheimer, 2000) may be modulated by means other than direct tyrosine kinase phosphorylation.

Although Kv1.5 coprecipitates with Src throughout development and differentiation in culture, we do not know whether the channel coprecipitates with Src enzymatic activity. However, the present study as well as others (Trotter et al., 1989; Barnett and Crouch, 1995; Weissenberger et al., 1997) has demonstrated that transfection with an enzymatically activated Src is sufficient to induce glial cells to proliferate, suggesting that the kinase activity of Src is high during gliogenesis in culture but is downregulated as glia stop proliferating and become differentiated.

The mechanisms by which Src family tyrosine kinase activity translates to changes in whole-cell Kv1.5 conductance remain to be investigated. Initial observations show no change in the voltage dependence nor in the slope of steady-state activation (our unpublished data). These findings are in agreement with those shown in Schwann cells, where tyrosine kinases suppress the amplitude of Kv1.5-mediated currents without altering gating properties (Peretz 
et al., 1999). Other studies have recorded current amplitude modulation by tyrosine kinase activity; for example, G-protein-coupled $\mathrm{mACh}$ receptor activation suppresses delayed rectifier activity via channel tyrosine phosphorylation (Huang et al., 1993), and growth factor receptor activation decreases Kv1.5 current amplitude in oocytes with little change in kinetics of activation (Timpe and Fantl, 1994). These changes in current amplitude could be brought about by changes in channel open probability just as Src has been shown to affect the single-channel open probability of NMDA receptors (Yu and Salter, 1999). Alternatively, phosphorylation could affect the number of channels in the membrane; however, in the present study this does not seem to be the case. We demonstrate that the Src inhibitor PP2 decreases Kv1.5 phosphorylation but does not alter the number of channels within the membrane, as assessed by biotinylation assays.

In neuronal cells, delayed rectifier potassium channels are particularly abundant in the axonal membrane, where they play key roles in modulating neuronal excitability and synaptic transmission by aiding in the repolarization of the membrane potential. Although no definitive functions have been attributed to potassium channels in astrocytes, the glial resting membrane potential depends almost exclusively on potassium conductance. Thus, these channels are integral in regulating membrane potential in both excitable and unexcitable cells. Membrane potential has long been implicated in the regulation of cell cycle progression (Cone, 1970), and delayed rectifier channels, in particular, have been implicated both directly (Knutson et al., 1997; MacFarlane and Sontheimer, 1997; Ghiani et al., 1999) and indirectly (Chiu and Wilson, 1989; Puro et al., 1989; Pappas et al., 1994; Gallo et al., 1996; Pappas and Ritchie, 1998) in glial cell proliferation. Thus, although the specific mechanisms by which potassium channel activity is regulated during proliferation require further investigation, we suggest that the activity of Src family protein tyrosine kinases may play a role in regulating proliferation-dependent channel activity in astrocytes.

\section{REFERENCES}

Akopian G, Kuprijanova E, Kressin K, Steinhauser C (1997) Analysis of ion channel expression by astrocytes in red nucleus brainstem slices of the rat. Glia 19:234-246.

Barnett SC, Crouch DH (1995) The effect of oncogenes on the growth and differentiation of oligodendrocyte type 2 astrocyte progenitor cells. Cell Growth Differ 6:69-80.

Bordey A, Sontheimer H (1997) Postnatal development of ionic currents in rat hippocampal astrocytes in situ. J Neurophysiol 78:461-477.

Cazaubon S, Chaverot N, Romero IA, Girault JA, Adamson P, Strosberg AD, Couraud PO (1997) Growth factor activity of endothelin-1 in primary astrocytes mediated by adhesio-dependent and -independent pathways. J Neurosci 17:6203-6312.

Chiu SY, Wilson GF (1989) The role of potassium channels in Schwann cell proliferation in Wallerian degeneration of explant rabbit sciatic nerves. J Physiol (Lond) 408:199-222.

Cone Jr CD (1970) Variation of the transmembrane potential level as a basic mechanism of mitosis control. Oncology 24:438-470.

Daub H, Wallasch C, Lankenau A, Herrlich A, Ullrich A (1997) Signal characteristics of G-protein-transactivated EGF receptor. EMBO J 16:7032-7044.

Fadool DA (1998) Tyrosine phosphorylation downregulates a potassium current in rat olfactory bulb neurons and a cloned Kv1.3 channel. Ann NY Acad Sci 855:529-532.

Fumagalli S, Totty NF, Hsuan JJ, Courtneidge SA (1994) A target for Src in mitosis. Nature 368:871-874.

Gallo V, Zhou JM, McBain CJ, Wright P, Knutson PL, Armstrong RC (1996) Oligodendrocyte progenitor cell proliferation and lineage progression are regulated by glutamate receptor-mediated $\mathrm{K}^{+}$channel block. J Neurosci 16:2659-2670.

Ghiani CA, Yuan X, Eisen AM, Knutson PL, DePinho RA, McBain CJ, Gallo V (1999) Voltage-activated $\mathrm{K}^{+}$channels and membrane depolarization regulate accumulation of the cyclin-dependent kinase inhibitors $\mathrm{p} 27(\mathrm{Kip} 1)$ and $\mathrm{p} 21(\mathrm{CIP} 1)$ in glial progenitor cells. J Neurosci 19:5380-5392.

Gulbins E, Szabo I, Baltzer K, Lang F (1997) Ceramide-induced inhibition of T-lymphocyte voltage-gated potassium channel is mediated by tyrosine kinases. Proc Natl Acad Sci USA 94:7661-7666.

Holmes TC, Fadool DA, Ren R, Levitan IB (1997) Association of Src tyrosine kinase with a human potassium channel mediated by $\mathrm{SH} 3$ domain. Science 274:2089-2091.

Huang XY, Morielli AD, Peralta EG (1993) Tyrosine kinase-dependent suppression of a potassium channel by the G-protein-coupled M1 muscarinic acetylcholine receptor. Cell 75:1145-1156.

Ivanina T, Perets T, Thornhill WB, Levin G, Dascal N, Lotan I (1994) Phosphorylation by protein kinase A of RCK1 K ${ }^{+}$channels expressed in Xenopus oocytes. Biochemistry 33:8786-8792.

Jonas EA, Kaczmarek LK (1996) Regulation of potassium channels by protein kinases. Curr Opin Neurobiol 6:318-323.

Knutson P, Ghiani CA, Zhou J-M, Gallo V, McBain C (1997) K ${ }^{+}$channel expression and cell proliferation are regulated by intracellular sodium and membrane depolarization in oligodendrocyte progenitor cells. J Neurosci 17:2669-2682.

Kobierski LA, Wong AE, Srivastava S, Borsook D, Hyman SE (1999) Cyclic AMP-dependent activation of the proenkephalin gene requires phosphorylation of CREB at serine-133 and a Src-related kinase. J Neurochem 73:129-138.

Kotecha SA, Schlichter LC (1999) A Kv1.5 to Kv1.3 switch in endogenous hippocampal microglia and a role in proliferation. J Neurosci 19:10680-10693.

Kressin K, Kuprijanova E, Jabs R, Seifert G, Steinhauser C (1995) Developmental regulation of $\mathrm{Na}^{+}$and $\mathrm{K}^{+}$conductances in glial cells of mouse hippocampal brain slices. Glia 15:173-187.

Levin G, Keren T, Peretz T, Chikvashvili D, Thornhill WB, Lotan I (1995) Regulation of RCK1 currents with a cAMP analog via enhanced protein synthesis and direct channel phosphorylation. J Biol Chem 270:14611-14618.

Levitan IB (1999) Modulation of ion channels by protein phosphorylation. How the brain works. Adv Second Messenger Phosphoprotein Res 33:3-22.

MacFarlane SN, Sontheimer H (1997) Electrophysiological changes that accompany reactive gliosis in vitro. J Neurosci 17:7316-7329.

MacFarlane SN, Sontheimer H (2000) Changes in ion expression accompany cell cycle progression of spinal cord astrocytes. Glia 30:40-49.

Moasser MM, Srethapakdi M, Sachar KS, Kraker AJ, Rosen N (1999) Inhibition of Src kinases by a selective tyrosine kinase inhibitor causes mitotic arrest. Cancer Res 59:6145-6152.

Oh Y (1997) Ion channels in neuroglial cells. Kao Hsiung I Hsueh Ko Hsueh Tsa Chih 13:1-9.

Pappas CA, Ritchie JM (1998) Effect of specific ion channel blockers on cultured Schwann cell proliferation. Glia 22:113-120.

Pappas CA, Ullrich N, Sontheimer H (1994) Reduction of glial proliferation by $\mathrm{K}^{+}$channel blockers is mediated by changes in pHi. NeuroReport 6:193-196.

Peretz A, Sobko A, Attali B (1999) Tyrosine kinases modulate $\mathrm{K}^{+}$channel gating in mouse Schwann cells. J Physiol (Lond) 519[Pt 2]:373-384.

Pomerance M, Gavaret JM, Breton M, Pierre M (1994) Growth factorregulated phosphatidylinositol-3-kinase in astrocytes. Involvement of pp60c-Src. Cell Mol Biol 40:653-664.

Pomerance M, Gavaret JM, Breton M, Pierre M (1995) Effects of growth factors on phosphatidylinositol-3 kinase in astroglial cells. J Neurosci Res 40:737-746.

Puro DG, Roberge F, Chan CC (1989) Retinal glial cell proliferation and ion channels: a possible link. Invest Ophthalmol Vis Sci 30:521-529.

Ransom CB, Sontheimer H (1995) Biophysical and pharmacological characterization of inwardly rectifying $\mathrm{K}^{+}$currents in rat spinal cord astrocytes. J Neurophysiol 73:333-346.

Roy ML, Sontheimer H (1995) $\beta$-Adrenergic modulation of glial inwardly rectifying potassium channels. J Neurochem 64:1576-1584.

Roy ML, Saal D, Perney T, Sontheimer H, Waxman SG, Kaczmarek LK (1996) Manipulation of the delayed rectifier Kv1.5 potassium channel in glial cells by antisense oligodeoxynucleotides. Glia 18:177-184.

Smart SL, Bosma MM, Tempel BL (1997) Identification of the delayed rectifier potassium channel, Kv1.6, in cultured astrocytes. Glia 20:127-134.

Sobko A, Peretz A, Attali B (1998a) Constitutive activation of delayedrectifier potassium channels by a Src family tyrosine kinase in Schwann cells. EMBO J 17:4723-4734.

Sobko A, Peretz A, Shirihai O, Etkin S, Cherepanova V, Dagan D, Attali B (1998b) Heteromultimeric delayed-rectifier $\mathrm{K}^{+}$channels in Schwann cells: developmental expression and role in cell proliferation. J Neurosci 18:10398-10408.

Sontheimer H (1994) Voltage-dependent ion channels in glia. Glia 11:155-172.

Sontheimer H, Trotter J, Schachner M, Kettenmann H (1989) Channel expression correlates with differentiation stage during the development of oligodendrocytes from their precursor cells in culture. Neuron 2:1135-1145.

Szabo I, Gulbins E, Apfel H, Zhang X, Barth P, Busch AE, Schlottmann K, Pongs O, Lang F (1996) Tyrosine phosphorylation-dependent suppression of a voltage-gated $\mathrm{K}^{+}$channel in T-lymphocytes on Fas stimulation. J Biol Chem 271:20465-20469. 
Szabo I, Nilius B, Zhang X, Busch AE, Gulbins E, Suessbrich H, Lang F (1997) Inhibitory effects of oxidants on $\mathrm{N}$-type $\mathrm{K}^{+}$channels in T-lymphocytes and Xenopus oocytes. Pflügers Arch 433:626-632.

Timpe LC, Fantl WJ (1994) Modulation of a voltage-activated potassium channel by peptide growth factor receptors. J Neurosci 14:1195-1201.

Trotter J, Boulter CA, Sontheimer H, Schachner M, Wagner EF (1989) Expression of v-Src arrests murine glial cell differentiation. Oncogene 4:457-464.

Weissenberger J, Steinbach JP, Malin G, Spada S, Rulicke T, Aguzzi A (1997) Development and malignant progression of astrocytomas in GFAP-v-Src transgenic mice. Oncogene 14:2005-2013.

Wiestler OD, Aguzzi A, Williams RL, Wagner EF, Boulter CA, Kleihues
P (1989) Tumor induction in fetal brain transplants exposed to the viral oncogenes polyoma middle T and v-Src. IARC Sci Publ 96:267-274.

Ye ZC, Rothstein JD, Sontheimer H (1999) Compromised glutamate transport in human glioma cells: reduction-mislocalization of sodiumdependent glutamate transporters and enhanced activity of cysteineglutamate exchange. J Neurosci 19:10767-10777.

Yu XM, Salter MW (1999) Src, a molecular switch governing gain control of synaptic transmission mediated by $N$-methyl-D-aspartate receptors. Proc Natl Acad Sci USA 96:7697-7704.

Zon G (1995) Antisense phosphorothioate oligonucleotides: introductory concepts and possible molecular mechanism of toxicity. Toxicol Lett $82: 419-424$ 